\title{
Assessment of Human Health Risk for Surface Sediments of Ikpoba River Contaminated by Heavy Metals
}

\author{
${ }^{* 1}$ ENUNEKU, AA; ${ }^{2}$ INEH, F \\ ${ }^{I}$ Department of Environmental Management and Toxicology, Faculty of Life Sciences, University of Benin City, Nigeria \\ ${ }^{2}$ Department of Animal and Environmental Biology, University of Benin, PMB 1154, Benin City, Nigeria. \\ *Corresponding Author Email: alex.enuneku@uniben.edu; Tel: +2348030773314
}

\begin{abstract}
Five heavy metals $(\mathrm{Cu}, \mathrm{Pb}, \mathrm{Ni}, \mathrm{Cd}, \mathrm{Fe})$ were accessed in surface sediments from Ikpoba River in Benin City, South of Nigeria; an area impacted by soil erosion and the Benin Water Storm project. The heavy metals were analysed using atomic absorption spectrometer. The mean concentrations of heavy metals were $0.543 \mathrm{mg} / \mathrm{kg}(\mathrm{Pb})$, $1.289 \mathrm{mg} / \mathrm{kg}(\mathrm{Ni}), 0.001 \mathrm{mg} / \mathrm{kg}(\mathrm{Cd}), 18.90143 \mathrm{mg} / \mathrm{kg}(\mathrm{Cu})$ and $1022 \mathrm{mg} / \mathrm{kg}(\mathrm{Fe})$ respectively. Human health risk assessment was used to assess the pollution degree of the river sediments. The results indicated that the pollution degree of heavy metals increased in the order $\mathrm{Fe}>\mathrm{Cu}>\mathrm{Ni}>\mathrm{Pb}>\mathrm{Cd}$. Human health risk assessment indicated that noncarcinogenic risks all fell below threshold level for both children and adults. The total carcinogenic risk due to $\mathrm{Pb}$ and $\mathrm{Cd}$ were within the acceptable range for both adults and children. The findings provide a scientific basis for the control of potentially toxic heavy metals concentrations and environmental protection of Ikpoba River.
\end{abstract}

\section{DOI: https://dx.doi.org/10.4314/jasem.v23i11.17}

Copyright: Copyright (C) 2019 Enuneku and Ineh. This is an open access article distributed under the Creative Commons Attribution License (CCL), which permits unrestricted use, distribution, and reproduction in any medium, provided the original work is properly cited.

Dates: Received: 07 October 2019; Revised: 11 November 2019; 24 November 2019

Keywords: Metals; Contamination Risk; River; Sediment

The freshwater environment has become contaminated with a wide range of pollutants, causing worldwide attention over the last few decades (Amoozadeh et al., 2014). One of these groups of contaminants are heavy metals. Heavy metals are naturally occurring, ubiquitous substances in the human environment, which typically originate from the weathering of parent materials. Nevertheless, due to a variety of human activities including mineral resources development, metal processing and smelting, industrial emissions, application of fertilizers and pesticides and atmospheric transportation (Chen et al., 2015), potentially toxic heavy metals have substantially accumulated in the global environment in recent years, particularly in sediment environments. Heavy metals are transported in various forms through the exchange of substances among ecosystems as they are highly mobile in air and water. In recent years, review and research articles have provided assessments of various kinds of soil heavy metal pollution all over the world, especially in developing countries. Some studies have indicated that fine sediments are carriers of heavy metals in the surface land flowing into the aquatic environment by surface runoff (Chowdhury et al., 2016). In the aquatic environment, potentially toxic elements can migrate with a carrier and are eventually absorbed by fine mineral particles in sediments and soils leading to contamination of aquatic environments. This has the potential to cause serious aquatic ecosystem and human health impairments (Xia et al., 2018). Elements such as metals dissolved in natural waters are easily absorbed by aquatic organisms and can rapidly bioaccumulate and affect man up the food chain. Studies have showed that $99 \%$ of heavy metals entering aquatic system are stored in sediments (Fang et al., 2019). River sediments are important repositories and carriers for heavy metals (Ikem, et al., 2003), Suspended sediments adsorb pollutants from the water, thus lowering their concentration in the water column. Heavy metals are inert in the sediment environment and are often considered to be conservative pollutants (Olivares-Rieumont et al., 2005). They are usually released into the water column in response to disturbances (Agarwal et al., 2005). Contamination of sediments with heavy metals is an environmentally important issue with consequences for aquatic organisms and human health, their quality can indicate the status of water pollution (Zahra et al., 2014). Sediments provide habitats and a food source for benthic fauna. Thus, pollutants may be directly or indirectly toxic to the aquatic flora and fauna. An analysis of the distribution of heavy metals in sediments adjacent to populated areas could be used to investigate anthropogenic impacts on ecosystems and would assist in the assessment of risks posed to humans. Several methods have been proposed for estimation of the potential risks to human health associated with heavy metals in sediments. The risks may be divided into carcinogenic and noncarcinogenic effects. The observed or predicted exposure concentrations are compared with thresholds for adverse effects, as determined by dose-effect relationships (Solomon et al., 1996). The aim of this study is to assess of human health risk for surface 
sediments of Ikpoba River contaminated by heavy metals.

\section{MATERIALS AND METHODS}

Ikpoba River (Lat $6.5^{\circ} \mathrm{N}$, Long $5.8^{\circ} \mathrm{E}$ ) is located in Benin City, Edo State in Southern Nigeria. Its headwater originates from North West of Benin City and flows north to south through the city (BenkaCoker and Ojior, 1995). The vegetation of Ikpoba River consists of rainforest which is secondary in nature and has been greatly subjected to deforestation and other anthropogenic activities. The study area is composed essentially of the secondary rainforest vegetation type and majorly composed of grasses, shrubs, epiphytic ferns, water hyacinth palm trees, bamboo trees, and rubber tree (Ibezute et al., 2016). The riparian communities are sparsely populated and their main activities are farming, fishing and palmwine tapping. Industrial wastes and water from drainage channel are discharged into the river at several points especially at the Benin City storm water discharge point.

Station $1\left(6.4532^{\circ} \mathrm{N}, 5.6095^{\circ} \mathrm{E}\right)$ was at the Iguosa Stretch of the River, Station $2\left(6.4513^{\circ} \mathrm{N}, 5.6162^{\circ} \mathrm{E}\right)$ was at Evwomore, Station $3\left(6.4105^{\circ} \mathrm{N}, 5.6372^{\circ} \mathrm{E}\right)$ was at Ekosodin axis, Station $4\left(6.4049^{\circ} \mathrm{N}, 5.6389^{\circ} \mathrm{E}\right)$ was at the Capitol directly under the bridge at the University of Benin, Station $5\left(6.3761^{\circ} \mathrm{N}, 5.6461^{\circ} \mathrm{E}\right)$ was at Upper Lawani (storm water discharge point), station $6\left(6.3517^{\circ} \mathrm{N}, 5.6467^{\circ} \mathrm{E}\right)$ was at the slaughter house and station $7\left(6.3343^{\circ} \mathrm{N}, 5.6636^{\circ} \mathrm{E}\right)$ was at the Guinness Brewery.

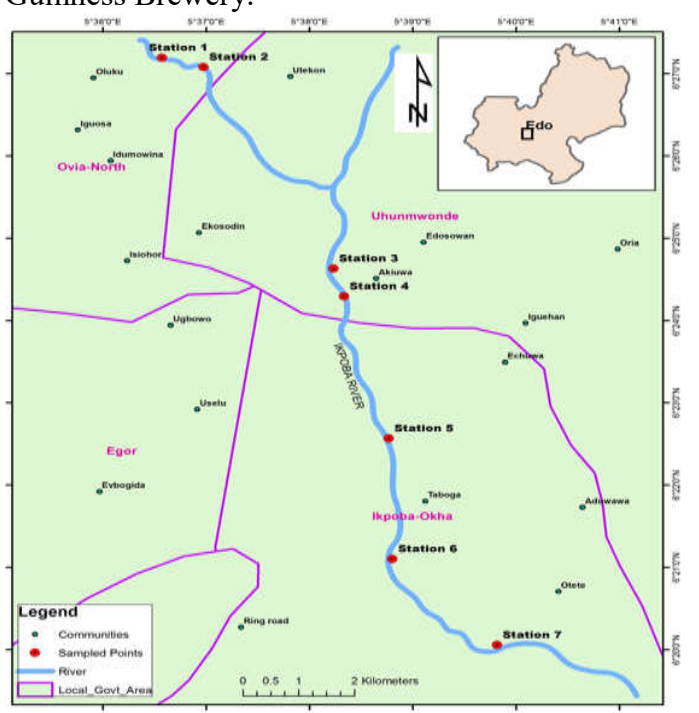

Fig 1: Map of Sampled Stations of Ikpoba River
Twenty-one (21) superficial sediment samples (0$5 \mathrm{~cm}$ ) (Maanan et al. 2015) were collected using a Van Veen grab from October to December 2018. They were collected from seven stations of the river beginning from the source downwards as it traverses the city. The sampled stations were chosen based on the prevailing stresses including the Benin City storm water discharge point.

All chemicals and reagents were analytical grade. Materials and reagents were used including $72 \%$ $\mathrm{HNO}_{3}$ (BDH), 37\% $\mathrm{HCl}$ (JHD). In order to construct the calibration curves, working standard solutions for $\mathrm{Cd}, \mathrm{Pb}, \mathrm{Cu}, \mathrm{Ni}, \mathrm{Fe}$ and $\mathrm{Zn}$ were freshly prepared by diluting an appropriate aliquot of standard solutions containing $1000 \mathrm{ppm}$ with serial concentrations for each element using $0.1 \% \mathrm{HNO}_{3}$. Glassware and polyethylene containers were cleaned and soaked in $10 \% \mathrm{HNO}_{3}$ for 48 hours and then rinsed thoroughly with deionized water.

In the laboratory, the soil samples were air dried for 48 hours and grounded with ceramic mortar and pestle. Digestion of soil samples was carried out after the modified method of Likuku et al. 2013 and Massadeh et al. 2017). Then $1 \mathrm{~g}$ of sample was digested in $10 \mathrm{ml}$ freshly prepared aqua regia $\left(3: 1, \mathrm{HNO}_{3}: \mathrm{HCl}\right)$ in a hot sand bath on a hot plate for 45 minutes. It was allowed to cool. Twenty (20) $\mathrm{ml}$ of distilled water was then added. Then it was filtered through a whatman filter paper $(110 \mathrm{~mm})$ into a $100 \mathrm{ml}$ standard flask. It was made up to mark with distilled water. Samples were then analysed for heavy metals using atomic absorption spectrophotometer (Buck Scientific, 210 VGP).

Human Health Risk Assessment: Human risk assessment is generally used to estimate the risk inflicted by the heavy metals of a particular concentration for human beings after chemical exposure (Kolluru et al., 1996). Hazard identification, exposure assessment, dose-response assessment, and risk characterization are the key elements of health risk assessment (NRC 1983). Health risk assessment can be determined by the non-carcinogenic and carcinogenic risk for both adults and children. To predict the human health risk caused by the exposure of heavy metals, chronic daily intake (CDI) $(\mathrm{mg} / \mathrm{kg} /$ day) through incidental ingestion (CDIingest) and dermal contact (CDIdermal) was determined by the following formulas (US EPA 1989)

$$
\begin{aligned}
& \qquad D I_{\text {ingest }}=\frac{C S \times I R \times C F \times F I \times E F \times E D}{B W \times A T} \\
& C D I_{\text {dermal }}=\frac{C S \times C F \times S A \times A F \times A B S \times E F \times E D}{B W \times A T} \\
& \text { is the ingestion rate (mg/day); } \quad \begin{array}{l}
\mathrm{CF} \text { is the conversion factor }(\mathrm{kg} / \mathrm{mg}) ; \mathrm{FI} \text { is the fraction } \\
\text { ingested from the contaminated source (unitless); the }
\end{array}
\end{aligned}
$$


$\mathrm{EF}$ of the CDIingest is the exposure frequency (days/year); ED is the exposure duration (years); BW is the average body weight $(\mathrm{kg})$; AT is the average time (days); SA is the exposed surface area of skin $\left(\mathrm{cm}^{2} /\right.$ event); AF is the skin adherence factor $\left(\mathrm{mg} / \mathrm{cm}^{2}\right)$; ABS is the dermal absorption factor (unitless); EF of CDIdermal is the exposure frequency (events/year). The values of the input parameters used to calculate CDI are given in Table 1.

Table 1. The values of parameters used to estimate chronic daily

\begin{tabular}{ll}
\multicolumn{2}{c}{ intake (CDI). } \\
\hline Parameter & Value \\
\hline IR & Child: $200 \mathrm{mg} /$ day; Adult: $100 \mathrm{mg} /$ day \\
CF & $1 \times 10^{-6} \mathrm{~kg} / \mathrm{mg}$ \\
FI & 1.0 \\
EF & 350 days/year \\
ED & Child: 6 years; Adult: 30 years \\
BW & Child: $15 \mathrm{~kg}$; Adult: $60 \mathrm{~kg}$ \\
AT & Non - carcinogenic: ED $\times 365$ days $/$ \\
& years; carcinogenic: 60 years $\times$ \\
& 365days/years \\
SA & Child: $2800 \mathrm{~cm}^{2} ;$ Adult: $5700 \mathrm{~cm}^{2}$ \\
AF & Child: $0.2 ;$ Adult: 0.07 \\
ABS & 0.001 \\
EF & 1 events/day $\times 350$ days $/$ year \\
\hline
\end{tabular}

Non-Carcinogenic Risk: Hazard index (HI) is characterized by the sum of hazard quotients (HQ), indicating the cumulative non-carcinogenic risks. HQ represents the ratio of the chronic daily intake (CDI) and the corresponding reference dose (RfD).

Carcinogenic Risk: Carcinogenic risk (CR) is estimated with the product of the chronic daily intake (CDI) and the cancer slope factor (CSF) over a lifetime. The cancer slope factor (CSF) plays a key role in convention that the daily toxin intake changes into the incremental risk of an individual developing cancer. CR and TCR are calculated by the following equations (US EPA 1989):

$C R=C D I \times C S F$

$T C R=\sum C R=$ CRingest + CRdermal

\section{RESULTS AND DISCUSSION}

The human health risks posed by potentially toxic heavy in Ikpoba River sediments were calculated according to the USEPA classification of carcinogens and non-carcinogens. $\mathrm{Cd}, \mathrm{Pb}, \mathrm{Zn}$, and $\mathrm{Cu}$ were investigated for their non-carcinogenic risks while $\mathrm{Cd}$ and $\mathrm{Ni}$ were assessed for their carcinogenic risks through ingestion and dermal route in both children and adults. Tables 2 and 3 presents the noncarcinogenic risks associated with non-dietary ingestion and dermal contact due to potentially toxic element exposure in sediments Based on the RfDingest, CDIingest and RfDdermal and CDIdermal the HQingest and HQdemal were calculated (Tables 2 and 3 ). The highest values of HQ via dermal contact was observed for $\mathrm{Cd}$ (0.0135), while the highest HQ via accidental ingestion was noted for $\mathrm{Cu}(0.00905)$ for adults. For children, the highest values of HQ via dermal contact was $(0.1178)$ for $\mathrm{Cd}$, while the highest $\mathrm{HQ}$ via accidental ingestion was $(0.0733)$ for $\mathrm{Cu}$. The values of this indicator, which refers to the health hazard of HMs to the workers, was in the order: $\mathrm{Cd}>$ $\mathrm{Cu}>\mathrm{Pb}>\mathrm{Ni}$ for dermal contact in adults while that of accidental ingestion was in the order of $\mathrm{Cu}>\mathrm{Ni}>\mathrm{Pb}$ $>\mathrm{Cd}$. In children, the values of this indicator was in the order: $\mathrm{Cd}>\mathrm{Cu}>\mathrm{Pb}>\mathrm{Ni}$ for dermal contact in adults while that of accidental ingestion was in the order of $\mathrm{Cu}>\mathrm{Ni}>\mathrm{Pb}>\mathrm{Cd}$ respectively.

All results of HQ for both accidental ingestion and dermal contact with sediments were lower than 1, indicating lack of carcinogenic risk for people with direct contact with this medium for about 60 years. The human health risk assessment is a powerful tool for distinguishing the potential toxicity of heavy metals and exposure routes of most concerns in urban environments (Dai et al., 2018).

Further research should track on any increase of $\mathrm{Cd}$ concentration in sediments, since (as it has been shown) $\mathrm{Cd}$ poses the highest risk to human health. The HI values of the studied heavy metals ranged from 0.00412 to 0.0135 for adults and from 0.003116 to 0.118 for children, respectively. HI values for children and adults investigated were in the order of $\mathrm{Cd}>\mathrm{Cu}$ $>\mathrm{Ni}>\mathrm{Pb}$.

The results suggested that there would not be a noncarcinogenic risk caused by heavy metals for children and adults, although the HI values for children were an order of magnitude higher than that for adults. The carcinogenic risk of $\mathrm{Ni}, \mathrm{Pb}$ and $\mathrm{Cd}$ was estimated for accidental ingestion for both adult and children, while only Cd was estimated for dermal contact because of the lack of slope factor. The CSF values of $\mathrm{Ni}$, and $\mathrm{Pb}$ and $\mathrm{Cd}$ are presented in table 2 (USEPA, 2012). CR through an individual exposure pathway can be summed to generate the total cancer risk (TCR).

A value of TCR ranging from $1 \times 10^{-6}$ to $1 \times 10^{-4}$ is considered an acceptable or tolerant scope (USEPA, 2012). A TCR less than $1 \times 10^{-6}$ does not have dramatic effects on human health, while a TCR exceeding $1 \times 10^{-}$ ${ }^{4}$ is regarded as unacceptable (USEPA, 2012). The CR values of $\mathrm{Ni}, \mathrm{Cd}$ and $\mathrm{Pb}$ on adults via accidental ingestion were $4.425 \times 10^{-8}, 4.80 \times 10^{-9}, 1.04 \times 10^{-5}$, while that of children where $8.30 \times 10^{-5}, 3.85 \times 10^{-7}, 3.54 \times 10^{-}$ ${ }^{7}$ The total cancer risk for Cadmium in children was $2.36 \times 10^{-1}$ and that of adults was $2.7 \times 10^{-2}$ As the same with $\mathrm{HI}$ values, the TCR values of adults were smaller than the children's values. The maximum acceptable risk level of $1 \times 10^{-4}$ is set by the US EPA. The CR values for children and adults suggested that these carcinogenic risk levels caused by $\mathrm{Ni}, \mathrm{Pb}$ and $\mathrm{Cd}$ were acceptable, while a TCR less the average TCR values for children and adults suggested that the carcinogenic risk levels caused by $\mathrm{Cd}$ might pose a carcinogenic risk to both children and adults. 
Table 2. The reference doses (RfDdermal), Chronic daily intake via dermal (ADDdermal), accidental ingestion (CDIingest), Hazard Quotient and Hazard Index in adults for the average concentrations of heavy metals at Ikpoba River.

\begin{tabular}{|c|c|c|c|c|c|c|c|c|c|c|}
\hline Metals & $\begin{array}{l}\mathrm{CS} \\
(\mathrm{mg} / \mathrm{kg})\end{array}$ & $\begin{array}{l}\text { RfDdexzual } \\
(\mathrm{mg} / \mathrm{kg} / \mathrm{day})\end{array}$ & $\begin{array}{l}\text { RfDlagest } \\
\text { (mg/kg/day) }\end{array}$ & $\begin{array}{l}\text { CDIderomal } \\
\text { (mg/kg/day) }\end{array}$ & $\begin{array}{l}\text { CDIingsest } \\
\text { (mg/kg/day) }\end{array}$ & HQderma? & HQingest & HI & SEingest & SEdscmal \\
\hline $\mathrm{Pb}$ & 0.543 & $5.25 \mathrm{E}-04$ & $1.40 \times 10^{-3}$ & $2.077 \mathrm{E}-07$ & $5.205 \mathrm{E}-06$ & $3.96 \mathrm{E}-04$ & $3.72 \mathrm{E}-03$ & 0.00412 & 0.0085 & - \\
\hline $\mathrm{Ni}$ & 1.289 & $5.40 \mathrm{E}-03$ & 0.003 & $4.930 \mathrm{E}-07$ & $1.24 \mathrm{E}-05$ & $9.13 \mathrm{E}-05$ & $4.13 \mathrm{E}-03$ & 0.00422 & 0.84 & - \\
\hline $\mathrm{Fe}$ & 1022.460 & - & - & $3.91 \mathrm{E}-04$ & 0.00984 & - & - & - & - & - \\
\hline $\mathrm{Cu}$ & 18.9014 & $1.20 \mathrm{E}-02$ & $2.00 \times 10^{-2}$ & $7.232 \mathrm{E}-06$ & 0.000181 & $6.03 \mathrm{E}-04$ & $9.05 \mathrm{E}-03$ & 0.00965 & - & - \\
\hline Cd & 0.001 & $1.00 \mathrm{E}-05$ & $3.00 \times 10^{-3}$ & $6.757 \mathrm{E}-07$ & $9.59 \mathrm{E}-09$ & $1.35 \mathrm{E}-02$ & $3.20 \mathrm{E}-06$ & 0.0135 & $5.01 \times 10^{-1}$ & $2.00 \times 10^{1}$ \\
\hline
\end{tabular}

Reference doses were adopted from US EPA, 2012; Ferreira and Miguel (2005).

Table 3. The reference doses (RfDdermal), average daily dosed via dermal (ADDdermal), accidental ingestion (CDIingest), Hazard Quotient and Hazard Index in children for the average concentrations of heavy metals at Ikpoba River

\begin{tabular}{|c|c|c|c|c|c|c|c|c|c|c|}
\hline Metals & $\begin{array}{l}\mathrm{CS} \\
(\mathrm{mg} / \mathrm{kg})\end{array}$ & $\begin{array}{l}\text { RfDdedsxapl } \\
(\mathrm{mg} / \mathrm{kg} / \mathrm{day})\end{array}$ & $\begin{array}{l}\text { RfDlugest } \\
(\mathrm{mg} / \mathrm{kg} / \mathrm{day})\end{array}$ & $\begin{array}{l}\text { CoDIderzual } \\
\text { (mg/kg/day) }\end{array}$ & $\begin{array}{l}\text { CDIfogest } \\
(\mathrm{mg} / \mathrm{kg} / \mathrm{day})\end{array}$ & HQdexanal & HOIngest & $\mathrm{HI}$ & SEin & SEdsconal \\
\hline $\mathrm{Bb}$ & 0.543 & $5.25 \mathrm{E}-04$ & $1.40 \times 10^{-3}$ & $7.671 \mathrm{E}-08$ & $4.164 \mathrm{E}-05$ & 0.0001461 & 0.00297 & 0.003116 & 0.0085 & - \\
\hline $\mathrm{Ni}$ & 1.289 & $5.40 \mathrm{E}-03$ & 0.003 & $2.798 \mathrm{E}-07$ & $9.885 \mathrm{E}-05$ & 0.00005181 & 0.03295 & 0.03295 & 0.84 & - \\
\hline $\mathrm{Fe}$ & 1022.460 & NA & $\mathrm{NA}$ & $2.22 \mathrm{E}-04$ & 0.0793 & - & - & - & - & - \\
\hline $\mathrm{Cu}$ & 18.9014 & $1.20 \mathrm{E}-02$ & $2.00 \times 10^{-2}$ & $4.104 E-06$ & 0.001466 & 0.000342 & 0.0733 & 0.0736 & - & - \\
\hline $\mathrm{Cd}$ & 0.001 & $1.00 \mathrm{E}-05$ & $3.00 \times 10^{-3}$ & $1.178 \mathrm{E}-06$ & $7.67 \mathrm{E}-07$ & 0.1178 & 0.000256 & 0.118 & $5.01 \times 10^{-1}$ & $2.00 \times 10^{1}$ \\
\hline
\end{tabular}

Reference doses were adopted from US EPA 2012

Conclusion: This study has shown that pollution degree of heavy metals in Ikpoba River increased in the order $\mathrm{Fe}>\mathrm{Cu}>\mathrm{Ni}>\mathrm{Pb}>\mathrm{Cd}$. Human health risk assessment indicated that non- carcinogenic risks all fell below threshold level for both children and adults. The total carcinogenic risk due to $\mathrm{Pb}$ and $\mathrm{Cd}$ were within the acceptable range for both adults and children. Monitoring of metal loads in Ikpoba River should be a continuous exercise in order to ensure that metal levels do not pose health risks to humans and biota.

\section{REFERENCES}

Amoozadeh E; Malek M; Rashidinejad R; Nabavi S; Karbassi M. (2014) Marine organisms as heavy metal bioindicators in the Persian Gulf and the Gulf of Oman. Environ. Sci. Pollut., 21: 23862395.

Agarwal A; Singh RD; Mishra SK. and Bhunya PK (2005). ANN-based sediment yield river basin models for Vamsadhara (India). Water SA, 31: 95-100.

Chen H; Teng Y; Lu S, Wang Y; Wang J. (2015) Contamination features and health risk of soil heavy metals in China. Sci. Total. Environ. 513:143-153.

Chowdhury S; Mazumder MA; Alattas O and Husain T. (2016) Heavy metals in drinking water: Occurrences, implications, and future needs in developing countries. Sci. Total Environ. 570:476-488.

Dai L; Wang L; Li L; Liang T; Zhang Y; Ma C. and Xing B. (2018). Multivariate geostatistical analysis and source identification of heavy metals in the sediment of Poyang Lake in China. Sci. Total Environ., 621:1433-1444.
Fang S; Longjiang M; Runxia S; Jijing D; Zhihai T. and Min D. (2019). Contamination Evaluation and Source Identification of Heavy Metals in the Sediments from the Lishui River Watershed, Southern China. Int. J. Environ. Res. Pub. Health, $16: 1-12$

Ferreira BL; Miguel ED. (2005). Geochemistry and risk assessment of street dust in Luanda, Angola: A tropical urban environment. Atmos. Environ., 39:4501-4512.

Ibezut CA; Asibor GI; Ibezute SU. (2016). Ecological Assessment of Brewery Effluent Impact on the Macrobenthic Invertebrates of Ikpoba River, Edo State, Nigeria. International Journal of Ecosystem, 6(3): 47-54.

Ikem A, Egiebor NO; Nyavor K. (2013). Trace Elements in Water, Fish and Sediment from Tuskegee Lake, Southeastern USA. Water Air Soil Pollut. 149: 51-75.

Kolluru RV; Bartell SM; Pitblado RM; Stricoff RS. (1996) Risk Assessment and Management Handbook; McGrow-Hill: New York, NY, USA.

Likuku AS; Mmolawa KB; Gaboutloeloe GK. (2013) Assessment of heavy metal enrichment and degree of contamination around copper-nickel mine in the Selebi Phikwe Region, Eastern Botswana. Environ. Ecol. Res, 1(2): 32-40.

Maanan M, Saddik M, Maanan M, Chaibi M, Assobhei O, Zourarah, B. (2015) Environmental and Ecological Risk Assessment of heavy metals in sediments of Nador Lagoon, Morocco. Ecological Indicators, 48: 616-626.

Massadeh AM; Al-Massaedh AAT; Kharibeh S. (2017) Determination of selected elements in canned food sold in Jordan markets. Environ. Sci. Pollut. Res. https://doi.org/10.1007/s11356-0170465-5. 
NRC (National Research Council) (1983) NAS (National Academy of Sciences). Risk Assessment in the Federal Government: Managing the Process; National Academy Press: Washington, DC, USA.

US EPA. (1989). Risk Assessment Guidance for Superfund Volume 1 Human Health Evaluation Manual (Part A); Office of Emergency and Remedial Response: Washington, DC, USA.

US EPA. (2012). Integrated Risk Information System of the US Environmental Protection Agency;
Office of Emergency and Remedial Response: Washington, DC, USA.

Xia F; Qu L; Qu LY; Wang T; Luo LL; Chen H; Dahlgren RA; Zhang MH; Mei K; Huang H. (2018). Distribution and source analysis of heavy metal pollutants in sediments of a rapid developing urban river system. Chemosphere, 207:218-228.

Zahra A; Hashmi MZ; Malik RN; Ahmed Z. (2014). Enrichment and geo-accumulation of heavy metals and risk assessment of sediments of the Kurang Nallah-Feeding tributary of the Rawal Lake Reservoir, Pakistan, Sci. Tot. Environ, 471: 925-933 
